\title{
DIELECTRIC STUDIES ON BINARY MIXTURES OF FORMAMIDE WITH ETHANOLAMINE USING THE TIME DOMAIN TECHNIQUE
}

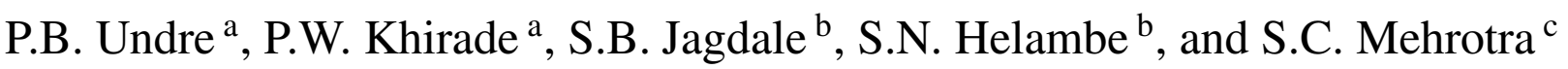 \\ ${ }^{a}$ Department of Physics, Dr. Babasaheb Ambedkar Marathwada University, Aurangabad-431 004, India \\ E-mail: prabhakarundre@yahoo.co.in \\ ${ }^{\mathrm{b}}$ Microwave Research Laboratory, Deogiri College, Aurangabad, India \\ ${ }^{\mathrm{c}}$ Department of Computer Science and Information Technology, Dr. Babasaheb Ambedkar Marathwada University, \\ Aurangabad-431 004, India
}

Received 29 January 2011; revised 3 March 2011; accepted 17 March 2011

\begin{abstract}
Dielectric relaxation measurements on formamide (FA) - ethanolamine (ETA) solvent mixtures have been carried out across the entire concentration range using time domain reflectometry technique at $15,25,35$, and $45^{\circ} \mathrm{C}$ over the frequency range from $10 \mathrm{MHz}$ to $10 \mathrm{GHz}$. The mixtures exhibit a principle dispersion of the Davidson-Cole relaxation type at microwave frequencies. Bilinear calibration method is used to obtain complex permittivity $\varepsilon^{*}(\omega)$ from complex reflection coefficient $\rho^{*}(\omega)$ over the frequency range $10 \mathrm{MHz}$ to $10 \mathrm{GHz}$. The excess permittivity $\varepsilon^{\mathrm{E}}$, excess inverse relaxation time $(1 / \tau)^{\mathrm{E}}$, Kirkwood correlation factor $g^{\text {eff }}$, and thermodynamic parameters such as Gibbs energy of activation $\Delta G$ and molar enthalpy of activation $\Delta H$ are also calculated to study the solute-solvent interaction.
\end{abstract}

Keywords: activation energy, excess parameters, Kirkwood correlation factor, time domain reflectometry

PACS: $77.22 . \mathrm{Ch}, 77.22 . \mathrm{Gm}$, 77.84.Nh

\section{Introduction}

The frequency dependent dielectric behaviour of solvent mixtures provides information on molecular interactions and mechanism of molecular process. The dielectric relaxation behaviour of mixtures of polar molecules under varying conditions of compositions is very important as it helps in obtaining information about relaxation process in mixtures. There have been several investigations on the dielectric behaviour of solvent mixtures in which dielectric relaxation spectra have been used to examine molecular orientations, hydrogen bonded networks, and microdynamics of these systems [1-12].

The dielectric relaxation study of formamide with alcohols [13, 14] and N,N-dimethylaminoethanol [8] mixtures over the entire range of concentration at that frequency ranging from $10 \mathrm{MHz}$ to $10 \mathrm{GHz}$ using time domain reflectometry technique have been reported earlier and strong interactive association between formamide and alcohol has been found.

Sengwa et al. obtained the complex dielectric spectra for $\mathrm{N}$-methylformamide and formamide [15] and formamide with dimethylsulphoxide and 1,4-dioxane [16] binary mixtures and confirmed that the unsimi- lar molecule hydrogen bond interaction strength was comparatively 1.5 times stronger in formamide-1,4dioxane mixtures as compared to the formamide-dimethylsulphoxide mixtures, and that it varied linearly with the values of dielectric constant and Kirkwood correlation factor of pure formamide. They also carried out the dielectric relaxation study of formamide with some common dipolar aprotic and protic solvents [17] (water, dimethylsulphoxide, N,N-dimethylformamide, acetone, 1,4-dioxane, mono-, di-, and trihydric alcohols, and homologous series of 2-alkoxyethanol, 2-(2alkoxyethoxy)ethanol, and ethylene glycol oligomers) binary mixtures at $30{ }^{\circ} \mathrm{C}$ over the frequency range $10 \mathrm{MHz}$ to $10 \mathrm{GHz}$ using time domain reflectometry (TDR). There they confirmed that the complexation strength of dipolar aprotic solvents with formamide strongly depended on the value of solvent dielectric constant.

Lou et al. investigated the dielectric properties of binary mixtures of 1-butanol-formamide at $21.4^{\circ} \mathrm{C}$ [7] and between $10-70{ }^{\circ} \mathrm{C}[18]$ over the frequency range of $200 \mathrm{MHz}-13.5 \mathrm{GHz}$. The dielectric spectra of the solvent mixtures could be fitted to the Debye model to obtain dielectric relaxation times and static dielectric 
constants as a function of temperature and solution composition. The free energy of activation for the dipolar relaxation process, $\Delta G$, and the Kirkwood correlation factor $g$ were determined using these fitting parameters for those solvent systems at various temperatures. The results provided useful descriptions of structures and thermodynamic properties of the solvent mixtures.

In this paper, a systematic investigation of dielectric relaxation in binary mixture of formamide (FA) with ethanolamine (ETA) at various concentration and temperature employing TDR [13-15] is reported. The dielectric relaxation spectra have been measured for the solutions at various compositions in the frequency range of $10 \mathrm{MHz}$ to $10 \mathrm{GHz}$, over a temperature range of 15 to $45^{\circ} \mathrm{C}$. The experimental data are fitted to the three different relaxation models [19-21] by the nonlinear least squares fit method and it is determined that the Davidson-Cole model is sufficient to describe the major dispersion of various solvents and solvent mixtures over this frequency range. Static dielectric constant and dielectric relaxation time could be obtained by fitting the spectra to Davidson-Cole model. The static dielectric constant and relaxation time are used to determine the excess permittivity, excess inverse relaxation time, Kirkwood correlation factor, and thermodynamic parameters such as free energy of activation $\Delta G$ and enthalpy of activation $\Delta H$. Kirkwood correlation factor characterizes the dipolar alignment within the solutions. The excess permittivity and excess inverse relaxation time give the information related to molecular interaction.

This binary system of FA and ETA is of interest because of two functional groups in ETA and with one common $\mathrm{NH}_{2}$ group in FA and ETA. One component of the system is aprotic (FA) and the second component is protic (ETA). FA and ETA both are polar with dipole moments 3.73 and 2.3 debye respectively. The dielectric study of binary system of these two solvents will give information about the interaction between $\mathrm{OH}$ and $\mathrm{NH}_{2}$ groups thereby forming different types of structure.

\section{Experiment}

FA and ETA were obtained commercially with $99.9 \%$ purity and were used without further purification. The solutions were prepared at different volume percentage of FA in ETA in the step of $10 \%$ at room temperature. The concentrations were prepared for $5 \mathrm{ml}$ solution at room temperature assuming ideal mixing behaviour, within $0.02 \%$ error limit.
The experimental procedure together with data analysis was described earlier [8, 9]. The complex permittivity spectra measured using TDR are fitted by the nonlinear least squares fit method to the Havriliak-Negami expression [22] to obtain various dielectric parameters:

$$
\varepsilon^{*}(\omega)=\varepsilon_{\infty}+\frac{\varepsilon_{0}-\varepsilon_{\infty}}{\left[1+(\mathrm{i} \omega \tau)^{1-\alpha}\right]^{\beta}},
$$

where $\varepsilon^{*}(\omega)$ is the complex permittivity at an angular frequency $\omega, \varepsilon_{\infty}$ is the permittivity at high frequency, $\varepsilon_{0}$ is the static permittivity, $\tau$ is the relaxation time of the system, $\alpha$ is the shape parameter representing symmetrical distribution of relaxation time, and $\beta$ is the shape parameter of an asymmetric relaxation curve. The value of $\varepsilon_{\infty}$ was taken to be 3.2 ; for the frequency range considered here, $\varepsilon^{*}$ is not sensitive to $\varepsilon_{\infty}$.

Frequency dependence curves for the dielectric dispersion $\varepsilon^{\prime}$ and absorption $\varepsilon^{\prime \prime}$ of FA-ETA with varying volume fraction of FA at $35^{\circ} \mathrm{C}$ are depicted in Figs. 1 and 2 , respectively. In the case of FA-ETA mixtures there is a considerable possibility of modifications in these homomolecular clusters, due to molecular interactions between the FA and ETA molecules. Apart from the complexities in the FA-ETA mixtures, the observed dielectric dispersion behaviour is a DavidsonCole type [23] for all the concentrations studied, and this is also the case for the individual molecules. Both the permittivity $\varepsilon^{\prime}$ (Fig. 1) and loss factor $\varepsilon^{\prime \prime}$ (Fig. 2) increase with increasing volume percentage of FA in the binary mixture ETA-FA at the low frequency end and decreases at the high frequency end. The frequency at which the loss factor is a maximum, $f_{\max }$ $\left(\tau=1 /\left(2 \pi f_{\max }\right)\right)$, shifts to higher values with increasing the volume percentage of FA in the mixture, corresponding to their individual relaxation times, because the individual molecular values are sufficiently different (i.e. 43.5 and $130 \mathrm{ps}$ ) to allow their resolution in practice.

Equation (1) includes Cole-Cole $(\beta=1)$ [24], Davidson-Cole $(\alpha=0)$ [23], and Debye $(\alpha=0, \beta=$ 1) [25] relaxation models. From the Cole-Cole plot shown in Fig. 3, the dielectric model for fitting dielectric parameters suitable for present system is DavidsonCole model. Therefore, the complex permittivity spectra has been fitted in Davidson-Cole model with $\alpha=$ 0 and $\beta(0<\beta \leq 1)$ as one of the fitting parameter along with $\varepsilon_{0}$ and $\tau$. The value of fitting parameter $\beta$ in Havriliak-Negami equation obtained is in the range of 0.7 to 0.82 for different concentrations. 


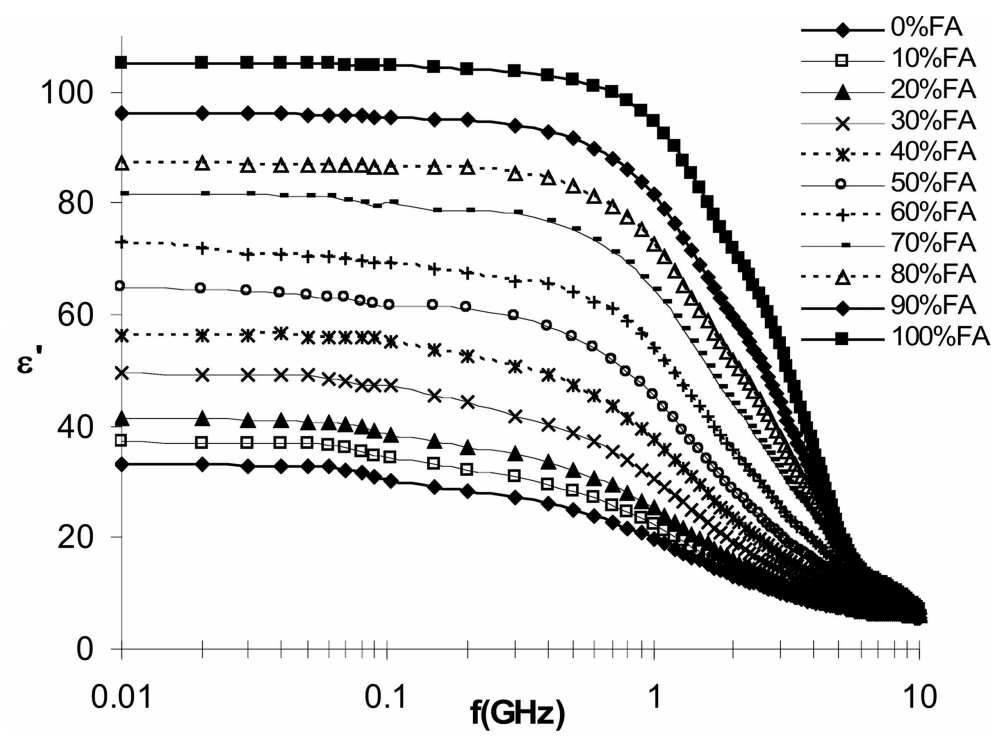

Fig. 1. Frequency dependent dielectric permittivity $\left(\varepsilon^{\prime}\right)$ curves for formamide, ethanolamine, and their mixtures at $35^{\circ} \mathrm{C}$.

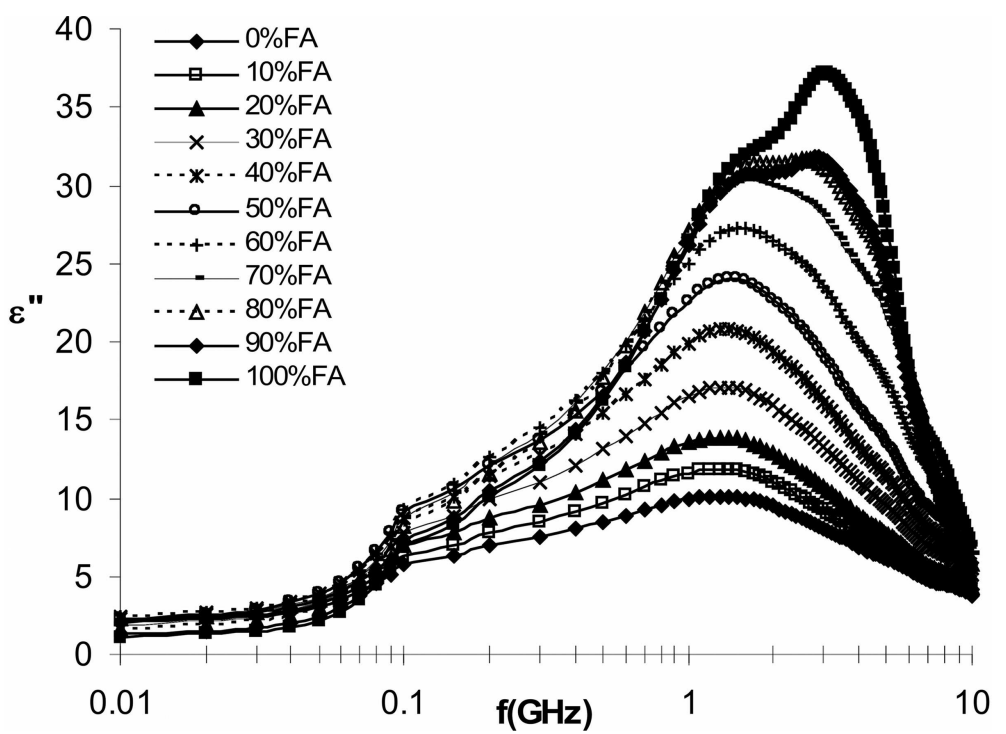

Fig. 2. Frequency dependent dielectric loss $\left(\varepsilon^{\prime \prime}\right)$ curves for formamide, ethanolamine, and their mixtures at $35^{\circ} \mathrm{C}$.

Table 1. Comparison of data for formamide with literature values at various temperatures

\begin{tabular}{|c|c|c|c|c|c|}
\hline \multicolumn{2}{|c|}{$\varepsilon_{0}$} & \multicolumn{2}{|c|}{$\tau, \mathrm{ps}$} & \multicolumn{2}{|c|}{$g$} \\
\hline This work & Literature & This work & Literature & This work & Literature \\
\hline $112.1515^{\circ} \mathrm{C}$ & $\begin{array}{l}111.25[20] \\
113.42[21]\end{array}$ & $51.5015^{\circ} \mathrm{C}$ & $51.6[20]$ & $2.0325^{\circ} \mathrm{C}$ & 2.09 [21] \\
\hline $110.2025^{\circ} \mathrm{C}$ & $\begin{array}{l}109.08[20] \\
109.56[21]\end{array}$ & & & & \\
\hline $105.1635^{\circ} \mathrm{C}$ & $105.21[21]$ & & & & \\
\hline
\end{tabular}


Table 2. Estimated static dielectric constant $\left(\varepsilon_{0}\right)$ and relaxation time $(\tau)$ for formamide-ethanolamine binary mixture at different temperatures.

\begin{tabular}{|c|c|c|c|c|c|c|c|c|}
\hline \multirow{2}{*}{$x_{\mathrm{FA}}$} & \multicolumn{2}{|c|}{$15^{\circ} \mathrm{C}$} & \multicolumn{2}{|c|}{$25^{\circ} \mathrm{C}$} & \multicolumn{2}{|c|}{$35^{\circ} \mathrm{C}$} & \multicolumn{2}{|c|}{$45^{\circ} \mathrm{C}$} \\
\hline & $\varepsilon_{0}$ & $\tau, \mathrm{ps}$ & $\varepsilon_{0}$ & $\tau, \mathrm{ps}$ & $\varepsilon_{0}$ & $\tau, \mathrm{ps}$ & $\varepsilon_{0}$ & $\tau, \mathrm{ps}$ \\
\hline 0 & $34.83(02)$ & $203.62(09)$ & $34.26(02)$ & $155.00(07)$ & $33.05(01)$ & $130.00(05)$ & $31.50(01)$ & $111.00(07)$ \\
\hline 0.1 & $38.68(26)$ & $202.00(89)$ & $38.13(24)$ & $149.85(40)$ & $37.16(21)$ & $126.25(11)$ & $34.75(15)$ & $105.94(60)$ \\
\hline 0.2 & $44.20(32)$ & $197.20(28)$ & $42.61(26)$ & $143.90(30)$ & $41.51(23)$ & $121.17(10)$ & $40.78(28)$ & $99.00(70)$ \\
\hline 0.3 & $52.05(36)$ & $179.61(50)$ & 49.95 (29) & $131.55(07)$ & $49.43(27)$ & $113.95(80)$ & $47.64(20)$ & $88.82(48)$ \\
\hline 0.4 & $61.59(38)$ & $154.12(30)$ & $59.43(34)$ & 121.97 (99) & $57.44(28)$ & $96.99(60)$ & $55.53(22)$ & $79.92(41)$ \\
\hline 0.5 & $72.44(45)$ & $141.00(30)$ & 67.87 (39) & $108.05(80)$ & $64.88(29)$ & $84.41(50)$ & $61.23(24)$ & $71.00(35)$ \\
\hline 0.6 & $80.49(41)$ & $115.60(75)$ & $76.75(38)$ & $93.21(60)$ & $73.23(31)$ & $74.34(40)$ & $69.49(22)$ & $60.00(24)$ \\
\hline 0.7 & 89.37 (47) & $96.73(70)$ & 84.99 (42) & $77.72(50)$ & $81.73(37)$ & $64.37(35)$ & $78.83(39)$ & $53.00(40)$ \\
\hline 0.8 & $95.50(45)$ & $77.55(48)$ & $91.79(45)$ & $66.40(44)$ & $87.19(48)$ & $57.29(42)$ & $85.44(30)$ & $50.73(25)$ \\
\hline 0.9 & $108.00(54)$ & $64.94(45)$ & $99.24(71)$ & $56.06(60)$ & $96.08(55)$ & $49.13(40)$ & $92.44(34)$ & $44.90(24)$ \\
\hline 1 & $112.15(01)$ & $51.50(03)$ & $110.20(05)$ & $46.30(04)$ & $105.16(06)$ & $43.50(04)$ & $97.77(05)$ & $39.50(03)$ \\
\hline
\end{tabular}

Number in parenthesis represents error, e. g., 34.26(02) means 34.26 \pm 0.02 . $x_{\mathrm{FA}}$ is volume fraction of formamide.

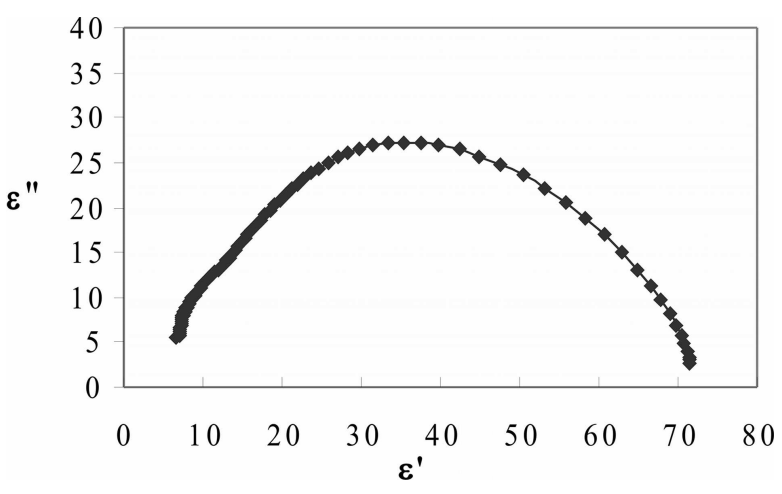

Fig. 3. Cole-Cole plot.

\section{Results and discussion}

The dielectric constant $\varepsilon_{0}$, relaxation time $\tau$, and Kirkwood correlation factor $g^{\text {eff }}$ of formamide along with their literature values are given in Table 1. The estimated values of $\varepsilon_{0}$ and $\tau$ obtained from fitting into Eq. (1) for FA, ETA, and FA-ETA mixtures with volume percentage of FA are recorded in Table 2. In the case of FA, good agreement had been found between the estimated values of dielectric constant $\varepsilon_{0}$, relaxation time $\tau$, and Kirkwood correlation factor $g^{\text {eff }}$ and literature data [26, 27]. It can be seen from Table 2 that with an increasing concentration of FA in ETA, the static dielectric constant values are increased, whereas the relaxation time values decrease with increase in volume percentage of FA in the solution. With increase in temperature, both static dielectric constant values and relaxation time values are decreasing by maintaining same type of change with change in concentration.

The excess parameters [6, 28] related to $\varepsilon_{0}$ and $\tau$ provide valuable information regarding interaction between the (solute-solvent) polar-polar liquid mixtures. These properties are also useful for detection of the co- operative domain in the mixture and may evidence formation of multimers in the mixture due to intermolecular interaction. The excess permittivity is defined as

$\varepsilon^{\mathrm{E}}=\left(\varepsilon_{0}-\varepsilon_{\infty}\right)_{\mathrm{m}}-\left[\left(\varepsilon_{0}-\varepsilon_{\infty}\right)_{A} x_{A}+\left(\varepsilon_{0}-\varepsilon_{\infty}\right)_{B} x_{B}\right]$

where $x$ is weight fraction and suffixes $m, A, B$ represent mixture, solvent $A$, and solvent $B$ respectively.

The excess permittivity provides qualitative information about multimer formation in the mixture as follows:

1. $\varepsilon^{\mathrm{E}}=0$ : indicates that the solute and solvent do not interact at all.

2. $\varepsilon^{\mathrm{E}}<0$ : indicates that the solute and solvent interaction act so as to reduce total effective dipoles. This suggests that the solute-solvent mixture may form multimers leading to the less effective dipoles.

3. $\varepsilon^{\mathrm{E}}>0$ : indicates that the solute and solvent interact in such a way that the effective dipole moment increases. There is formation of multimers and dimers. Earlier in [28-31], $\varepsilon^{\mathrm{E}}$ was evaluated to confirm the formation of multimers and their nature in different binary mixtures of associating polar molecules.

Figure 4 shows the plot of excess permittivity against molar fraction of FA for all temperatures. In this study, the excess permittivity values are found to be negative for all temperatures and concentrations, indicating that the total number of dipoles decreases in the FA-ETA mixtures. This is due to the opposite alignment of the dipoles of the interacting FA and ETA molecules. The excess permittivity values are more negative at around 0.2 molar fraction of formamide. This indicates the stronger reduction in total number of dipoles in the solution in this region. Further, the low value of $\varepsilon^{\mathrm{E}}$ at 


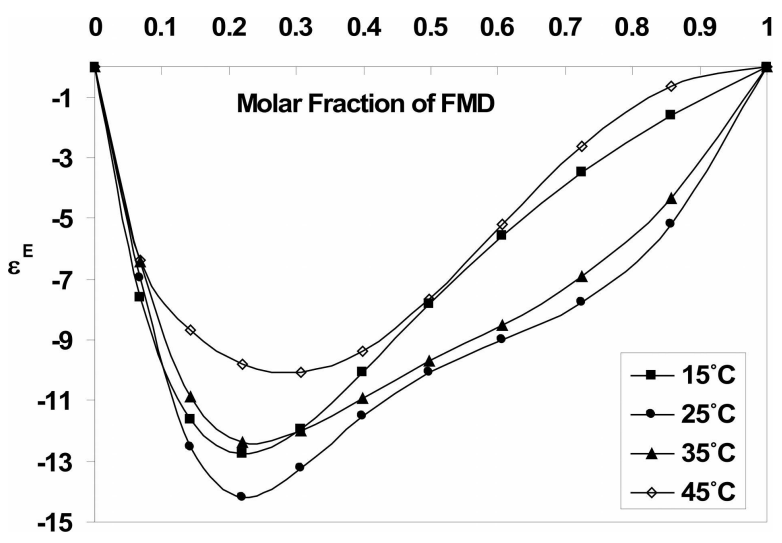

Fig. 4. Variation of estimated excess permittivity as function of molar fraction of formamide in ethanolamine at different temperatures.

concentrations near that of pure FA indicates that there is less interaction between FA and ETA molecules.

The excess inverse relaxation time is defined as

$$
(1 / \tau)^{\mathrm{E}}=(1 / \tau)_{\mathrm{m}}-\left[(1 / \tau)_{A} x_{A}+(1 / \tau)_{B} x_{B}\right],
$$

where $(1 / \tau)^{\mathrm{E}}$ is excess inverse relaxation time, which represents average broadening of dielectric spectra. The inverse relaxation time analogy is taken from spectral line broadening (which is the inverse of relaxation time) from the resonant spectroscopy [7]. The information regarding the dynamics of solute-solvent interaction from this excess property is as follows:

1. $(1 / \tau)^{\mathrm{E}}=0$ : there is no change in the dynamics of solute-solvent interaction.

2. $(1 / \tau)^{\mathrm{E}}<0$ : the solute-solvent interaction produces a field such that the effective dipoles rotate slowly.

3. $(1 / \tau)^{\mathrm{E}}>0$ : the solute-solvent interaction produces a field such that the effective dipoles rotate rapidly i. e. the field will co-operate in rotation of dipoles.

The variation of $(1 / \tau)^{\mathrm{E}}$ with molar fraction of FA for all the four temperatures is shown in Fig. 5. From there it can be seen that, for all temperatures, the excess inverse relaxation time values are negative, which indicates the formation of linear structure rotating slowly under the influence of an external varying field. It follows that addition of FA to ETA has created a hindering field such that the effective dipoles rotate slowly. The excess values are more negative at around 0.4 molar fraction of FA in the solution. The same type of change has been observed at all temperatures under study.

The structural information about the liquid from dielectric relaxation can be obtained by studying the Kirkwood correlation parameter [32]. The Kirkwood correlation factor $g$ is also a parameter providing information

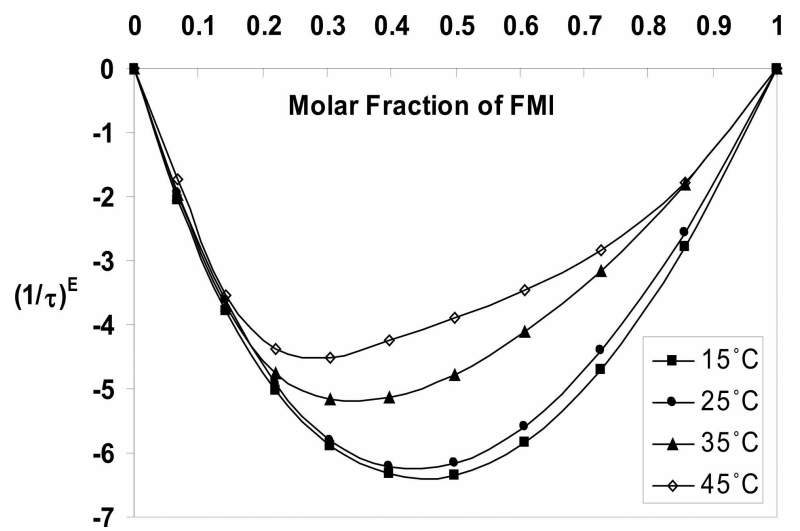

Fig. 5. Variation of estimated excess inverse relaxation time as function of molar fraction of formamide in ethanolamine at different temperatures.

on orientation of electric dipoles in polar liquids. The $g$ for pure liquid can be obtained by the expression

$$
\frac{4 \pi N \mu^{2} \rho}{9 k T M} g=\frac{\left(\varepsilon_{0}-\varepsilon_{\infty}\right)\left(2 \varepsilon_{0}+\varepsilon_{\infty}\right)}{\varepsilon_{0}\left(\varepsilon_{\infty}+2\right)^{2}}
$$

where $\mu$ is the dipole moment in gas phase, $\rho$ is density at temperature $T, M$ is molecular weight, $k$ is Boltzmann constant, $N$ is Avogadro's number.

The effective angular correlation $g^{\text {eff }}$ between molecules is calculated using a modified form of Eq. (4) [6, 33]. The $g^{\text {eff }}$ has been used to study the orientation of electric dipoles in binary mixtures. The Kirkwood equation for the mixture may be expressed as [6, 33]

$$
\begin{aligned}
& \frac{4 \pi N}{9 k T}\left[\frac{\mu_{A}^{2} \rho_{A}}{M_{A}} \Phi_{A}+\frac{\mu_{B}^{2} \rho_{B}}{M_{B}} \Phi_{\mathrm{B}}\right] g^{\text {eff }} \\
& =\frac{\left(\varepsilon_{0 m}-\varepsilon_{\infty m}\right)\left(\varepsilon_{0 m}+\varepsilon_{\infty m}\right)}{\varepsilon_{0 m}\left(\varepsilon_{\infty m}+2\right)^{2}},
\end{aligned}
$$

where $g^{\text {eff }}$ is the effective Kirkwood correlation factor for a binary mixture and $\Phi_{A}, \Phi_{B}$ are volume fractions of liquids $A$ and $B$.

The calculated values of $g^{\text {eff }}$ are tabulated in Table 3 . It can be seen that $g^{\text {eff }}$ value for pure ETA is greater than that of pure FA. The values of correlations factor in the solution for various volume fractions of formamide decrease up to 0.3 volume fraction of formamide in the solution. This indicates the decrease in interaction between the molecules of the system with the increase in volume fraction of formamide. Further increase in volume fraction of FA only slightly change the interaction between the molecules of the system. Since the ETA is a protic solvent, hydrogen bonding prevails, which gives more interaction of the molecules of the system in ETA rich region. 
Table 3. Estimated values of Kirkwood correlation factor $\left(g^{\text {eff }}\right)$ in the formamide-ethanolamine solution.

\begin{tabular}{ccccc}
\hline & \multicolumn{4}{c}{$g^{\text {eff }}$} \\
\cline { 2 - 5 } & $15^{\circ} \mathrm{C}$ & $25{ }^{\circ} \mathrm{C}$ & $35^{\circ} \mathrm{C}$ & $45^{\circ} \mathrm{C}$ \\
\hline 0.0 & 2.41 & 2.45 & 2.44 & 2.40 \\
0.1 & 2.07 & 2.11 & 2.13 & 2.05 \\
0.2 & 1.93 & 1.93 & 1.94 & 1.96 \\
0.3 & 1.92 & 1.91 & 1.95 & 1.94 \\
0.4 & 1.97 & 1.97 & 1.97 & 1.96 \\
0.5 & 2.05 & 1.98 & 1.96 & 1.91 \\
0.6 & 2.04 & 2.01 & 1.98 & 1.94 \\
0.7 & 2.05 & 2.01 & 2.00 & 1.99 \\
0.8 & 1.99 & 1.98 & 1.95 & 1.97 \\
0.9 & 2.08 & 1.97 & 1.97 & 1.96 \\
1.0 & 1.99 & 2.03 & 2.00 & 1.92 \\
\hline
\end{tabular}

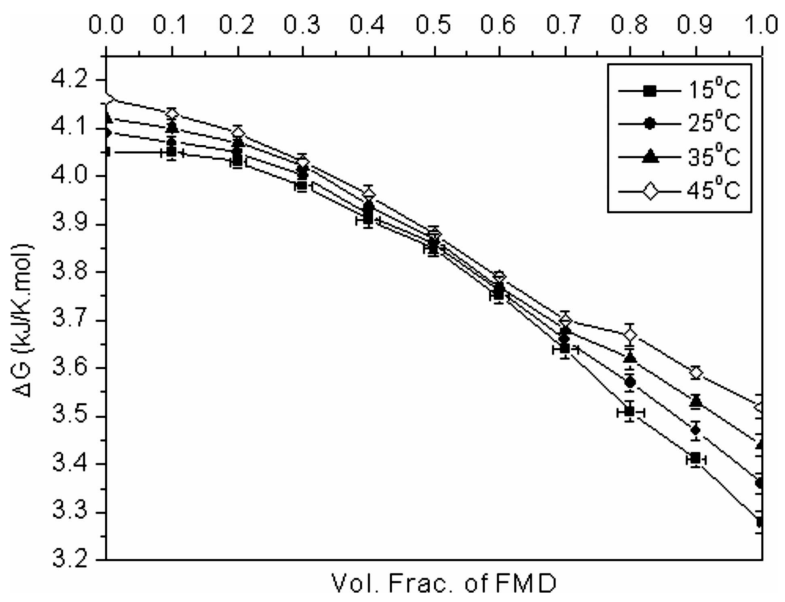

Fig. 6. Variation of Gibbs energy of activation $(\Delta G)$ for the dipolar relaxation for FA-ETA binary mixture as a function of solution composition.

Since the Arrhenius plots of $\log \tau$ versus $1 / T$ displayed a good linearity for all the studied liquid mixtures, the thermodynamic parameters, such as Gibbs energy of activation $\Delta G$ and molar enthalpy of activation $\Delta H$ that characterize the molecular mobility in those systems, were evaluated using the Eyring formula [34, 35].

The systems show Arrhenius behaviour. Figure 6 shows Gibbs energy of activation $\Delta G$ of the FA-ETA mixture as a function of solution composition at different temperatures. It is observed that $\Delta G$ values of ETA are 0.64 to $0.77 \mathrm{~kJ} /(\mathrm{K} \mathrm{mol})$ higher than those of FA over the temperature range $15-45^{\circ} \mathrm{C}$. Despite the distinct difference in $\Delta G$ values of ETA and FA and the presence of hydrogen bonding between ETA and FA molecules, there is a gradual decrease in $\Delta G$ with increase in volume fraction of FA, which suggests that the FA and ETA molecules in the mixture react to the external field in a strongly cooperative way rather than indi-

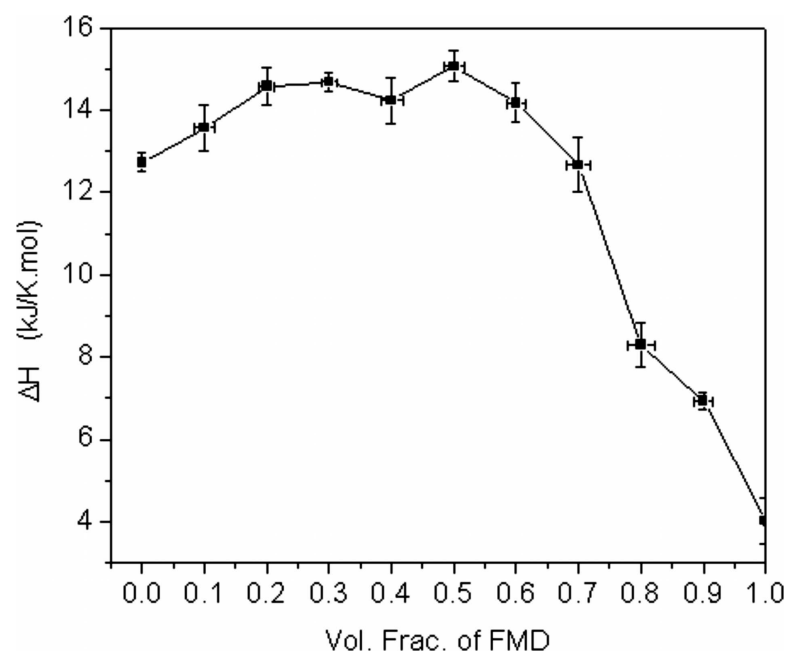

Fig. 7. Variation of molar enthalpy of activation $(\Delta H)$ for FA-ETA binary mixture.

vidually over the temperature range of $15-45^{\circ} \mathrm{C}$. It also suggests that there is more hindrance to the rotation of the FA and ETA molecule clusters in FA-ETA in comparison with the rotation of their homogeneous clusters. This also supports the conclusions drawn from the negative values of the excess inverse relaxation time.

The values of molar enthalpy of activation $\Delta H$ in $\mathrm{kJ} /(\mathrm{K} \mathrm{mol})$ are obtained from Eyring's rate equation for FA, ETA, and FA-ETA binary mixtures. The plot of $\Delta H$ with variation in volume fraction of FA in FAETA mixtures is shown in Fig. 7. The value of $\Delta H$ gradually increases with increase in volume fraction of FA in ETA, from 12.37 up to $15.07 \mathrm{~kJ} /(\mathrm{K} \mathrm{mol})$, up to 0.5 volume fraction of $F A$, except $14.24 \mathrm{~kJ} /(\mathrm{K} \mathrm{mol})$ at 0.4 volume fraction FA. This indicates that more energy is needed for group dipole reorientation with increase in volume fraction of FA in the mixture. There is an increase in agitation with increase in volume fraction of FA up to 0.5 volume fraction in the mixture, which may be due to the interaction in amino $\left(\mathrm{NH}_{2}\right)$ and hydroxyl $(\mathrm{OH})$ group or amino-amino group. Further $\Delta H$ decreases to the $\Delta H$ of FA $(4.02 \mathrm{~kJ} /(\mathrm{K} \mathrm{mol}))$. The large value of $\Delta H$ is observed at 0.5 volume fraction of $\mathrm{FA}$ indicating a strong hydrogen bonding in this solution mixture.

The most probable relaxation time determined for the FA-ETA binary mixture decreases with increasing temperature. In general, this type of temperature dependent effect could indicate either a temperature dependent rate process with activation energy or an equilibrium process with an enthalpy change between the two (or perhaps more) states, $\Delta H$. 


\section{Conclusions}

The binary mixture of formamide and ethanolamine has been studied in the frequency range of $10 \mathrm{MHz}$ to $10 \mathrm{GHz}$. The static dielectric constant of ETA is found to be lower than that of FA. In mixture of FA and ETA, the static dielectric constant increases with increase in concentration of FA in the solution.

The relaxation time of ETA is found to be much higher than that of FA. This is due to more hydrogen bonding due to $\mathrm{OH}$ group in ETA. The value of relaxation time in the solution decreases with increase in concentration of FA. The rate of decrease is exponential rather than linear. This indicates that there is more influence of ETA in forming the structures of higher relaxation time. The excess static permittivity and excess inverse relaxation time values are negative in the solution.

The $g^{\text {eff }}$ values decrease rapidly up to $20 \%$ FA and remain almost constant with increase in concentration of FA in the solution. The studied systems show Arrhenius behaviour. The Gibbs energy of activation is dependent of the temperature for all concentrations in the temperature range of $15-45^{\circ} \mathrm{C}$. The enthalpy of activation increases up to 0.5 volume fraction of FA in the mixture.

\section{References}

[1] A. Choudhari, H. Choudhari, and S.C. Mehrotra, J. Chin. Chem. Soc. 49, 489 (2002).

[2] K. Dharmalingam, K. Ramachandran, P. Sivagurunathan, P. Undre, P.W. Khirade, and S.C. Mehrotra, Bull. Kor. Chem. Soc. 27(12), 2040 (2006).

[3] K. Dharmalingam, K. Ramachandran, P. Sivagurunathan, P. Undre, P.W. Khirade, and S.C. Mehrotra, Mol. Phys. 104(18), 2835 (2006).

[4] K. Dharmalingam, K. Ramachandran, P. Sivagurunathan, P. Undre, P.W. Khirade, and S.C. Mehrotra, Chem. Papers Chem. Zvesti 61(4), 300 (2007).

[5] K. Dharmalingam, K. Ramachandran, P. Sivagurunathan, P. Undre, P.W. Khirade, and S.C. Mehrotra, J. Appl. Poly. Sci. 107, 2312 (2008).

[6] A.C. Kumbharkhane, S.M. Puranik, and S.C. Mehrotra, J. Sol. Chem. 22, 219 (1993).

[7] J. Lou, T.A. Hatton, and P.E. Laibinis, J. Phys. Chem. A 101, 5262 (1997).

[8] Prabhakar Undre, S.N. Helambe, S.B. Jagdale, P.W. Khirade, and S.C. Mehrotra, Pramana J. Phys. 68(5), 851 (2007).

[9] Prabhakar Undre, S.N. Helambe, S.B. Jagdale, P.W. Khirade, and S.C. Mehrotra, J. Mol. Liq. 137, 147 (2008).
[10] V.P. Pawar and S.C. Mehrotra, J. Mol. Liq. 95, 63 (2002).

[11] P. Sivagurunathan, K. Dharmalingam, K. Ramachandran, P. Undre, P.W. Khirade, and S.C. Mehrotra, Main Group Chem. 4(3), 235 (2005).

[12] P. Sivagurunathan, K. Dharmalingam, K. Ramachandran, P. Undre, P.W. Khirade, and S.C. Mehrotra, Physica B 387, 203 (2007).

[13] U. Sankar, G. Parthipan, P. Undre, P.W. Khirade, T. Thenappan, and S.C. Mehrotra, Main Group Chem. 8(2), 61 (2009).

[14] K. Ramachandran, K. Dharmalingam, P. Sivagurunathan, Prabhakar Undre, P.W. Khirade, and S.C. Mehrotra, Main Group Chem. 4(4), 303 (2005).

[15] R.J. Sengwa, Vinita Khatri, and Sonu Sankhla, J. Sol. Chem. 38, 763 (2009).

[16] R.J. Sengwa, Sonu Sankhla, and Vinita Khatri, J. Mol. Liq. 151, 17 (2010).

[17] R.J. Sengwa, Vinita Khatri, Sonu Sankhla, J. Mol. Liq. 144, 89 (2009).

[18] Jianfeng Lou, A.K. Paravastu, P.E. Laibinis, and T.A. Hatton, J. Phys. Chem. A 101, 9892 (1997).

[19] S. Mashimo, S. Kuwabara, S. Yogihara, and K. Higasi, J. Chem. Phys. 90, 3292 (1989).

[20] R.H. Cole, J.G. Berbarian, S. Mashimo, G. Chryssikos, A. Burns, and E. Tombari, J. Appl. Phys. 66, 793 (1989).

[21] S.M. Puranik, A.C. Kumbharkhane, and S.C. Mehrotra, J. Microw. Power Electromagn. Energy 26, 196 (1991).

[22] S. Havriliak and S. Negami, J. Polymer Sci. Part C 14, 99 (1966).

[23] D.W. Davidson and R.H. Cole, J. Chem. Phys. 18, 1484 (1950).

[24] K.S. Cole and R.H. Cole, J. Chem. Phys. 9, 341 (1941).

[25] P. Debye, Polar Molecules (The Chemical Catalogue Company, New York, 1929).

[26] S.M. Puranik, A.C. Kumbharkhane, and S.C. Mehrotra, Indian J. Chem. A 32, 613 (1993).

[27] J. Barthel, R. Buchner, and Wurm Bernhard, J. Mol. Liq. 98-99, 51-69 (2002).

[28] M. Tabellout, P. Lanceleur, and J.R. Emery, J. Chem. Soc. Faraday Trans. 86, 1493 (1990).

[29] S. Ahire, A. Chaudhari, M. Lokhande, and S.C. Mehrotra, J. Solution Chem. 27, 993 (1998).

[30] P.W. Khirade, A. Chaudhari, J.B. Shinde, S.N. Helambe, and S.C. Mehrotra, J. Solution Chem. 28, 1037 (1999).

[31] S.N. Helambe, M.P. Lokhande, A.C. Kumbharkhane, S.C. Mehrotra, and S. Doraiswamy, Pramana-J. Phys. 44(5), 405 (1995).

[32] H. Fröhlich, Theory of Dielectrics (Oxford University Press, London, 1949).

[33] G. Moumouzias, D.K. Panopoulos, and G. Ritzoulis, J. Chem. Eng. Data 36, 20 (1991). 
[34] N.E. Hill, W.E. Vaughan, A.H. Price, and M. Davies, Dielectric Properties and Molecular Behaviour (Reinhold, London, 1969).
[35] S. Glasstone, K.J. Laidler, and H. Eyring, Theory of Rate Processes (McGraw-Hill Book Co., New York, 1941) $548 \mathrm{p}$.

\title{
DVINARIŲ FORMAMIDO IR ETANOLAMINO MIŠINIŲ DIELEKTRINIS TYRIMAS LAIKINĖS REFLEKTOMETRIJOS METODU
}

\author{
P.B. Undre ${ }^{\text {a }}$, P.W. Khirade ${ }^{\text {a }}$, S.B. Jagdale ${ }^{\text {b }}$, S.N. Helambe ${ }^{\text {b }}$, S.C. Mehrotra ${ }^{c}$ \\ ${ }^{\text {a }}$ Dr. Babasaheb Ambedkar Marathwada universiteto Fizikos katedra, Aurangabadas, Indija \\ ${ }^{\mathrm{b}}$ Mikrpbangu tyrimo laboratorija, Deogiri koledžas, Aurangabadas, Indija \\ ${ }^{\mathrm{c}}$ Dr. Babasaheb Ambedkar Marathwada universiteto Kompiuterijos ir informaciniu technologiju katedra, Aurangabadas, Indija
}

\section{Santrauka}

Laikinès reflektometrijos metodu matuota formamido (FA) ir etanolamino (ETA) tirpalų mišinių dielektrinè relaksacija visame koncentracijų diapazone esant $15,25,35$ ir $45^{\circ} \mathrm{C}$ temperatūrai ir dažniui nuo $10 \mathrm{MHz}$ iki $10 \mathrm{GHz}$. Mikrobangų dažnių diapazone pagrindinè mišinių dispersija yra Davidson-Cole relaksacijos tipo. Kompleksinei skvarbai $\varepsilon^{*}(\omega)$ iš kompleksinio atspindžio gauti daž- nių nuo $10 \mathrm{MHz}$ iki $10 \mathrm{GHz}$ diapazone taikomas dvitiesinio kalibravimo metodas. Tirpintos medžiagos ir tirpiklio sąveikai tirti taip pat skaičiuoti perteklinè skvarba $\left(\varepsilon^{\mathrm{E}}\right)$, perteklinè atvirkštinè relaksacijos trukmé $(1 / \tau)^{\mathrm{E}}$, Kirkwoodo koreliacijos faktorius $\left(g^{\text {eff }}\right)$ ir termodinaminiai parametrai, tokie kaip Gibso aktyvacijos energija $(\Delta G)$ bei molinè aktyvacijos entalpija $(\Delta H)$. 